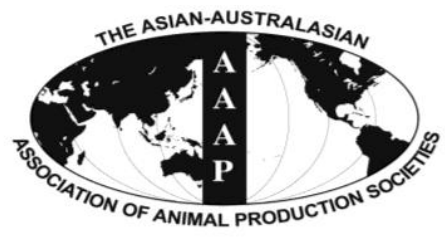

Asian Australas. J. Anim. Sci.

Vol. 26, No. 5 : 675-682 May 2013

http://dx.doi.org/10.5713/ajas.2012.12086

www.ajas.info

pISSN 1011-2367 elSSN 1976-5517

\title{
Effects of Supplemental Levels of Bazhen on Growth Performances, Serum Traits, Immunity, Meat Quality and Antioxidant Activity of Taiwan Country Chickens
}

\author{
Tu-Fa Lien*, Kou-Joong Lin, Ling-Ling Yang ${ }^{1}$ and Lih-Geeng Chen ${ }^{2}$ \\ Department of Animal Science, National Chiayi University, 300 University Road, Luh Liau Li, Chiayi, Taiwan
}

\begin{abstract}
One hundred and sixty Taiwan country chickens (d-old chicks) were randomly assigned into four groups with four replicates and equal sex. Basal diets were supplemented with 0, 0.5, 1 and 2\% of Bazhen powder, a traditional Chinese herbal medicine complex. The study was conducted for 14 wks. Experimental results indicated that Bazhen supplement did not influence feed intake, body weight gain and feed:gain ratio. Compared with control group, the percentage of serum HDL (high-density lipoprotein) linearly increased $(\mathrm{p}<0.03)$ and that of VLDL+LDL (very low-density+low-density lipoprotein) linearly decreased $(\mathrm{p}<0.03)$ in Bazhen supplemented groups, that $2 \%$ Bazhen was significantly different with control group $(\mathrm{p}<0.05)$. Chickens fed diets containing $2 \%$ Bazhen displayed reduced $(\mathrm{p}<0.05)$ serum GOT (glutamic-oxaloacetic transaminase) levels. The IgG, $\gamma$-globulin levels and PHA (phytohemagglutinin) skin challenge results in $1 \%$ Bazhan supplemented group were higher $(\mathrm{p}<0.05)$ than in the control group, the SRBC (sheep red blood cell) and ND (newcastle disease) titers in Bazhen supplemented groups were linear higher $(p<0.05)$ than in the control group. The liver catalase activity and the capacity of scavenging DPPH ( $\alpha$ - $\alpha$-diphenyl- $\beta$-picrylhydrazyl) radical were linearly increased $(\mathrm{p}<0.03)$ in Bazhen supplemented groups, and the 1 and $2 \%$ groups were different from the control group ( $\mathrm{p}<0.05)$. Liver TBARS (thiobarbituric acid-reactive substances) levels in all Bazhen supplemented groups and total glutathione level in the $2 \%$ group were reduced $(\mathrm{p}<0.05)$ compared to the control group and displayed a linear response $(\mathrm{p}<0.05)$. The TBA (thiobarbituric acid) and $\mathrm{pH}$ value of the breast muscle after $24 \mathrm{~h}$ post-mortem in the Bazhen supplemented groups was linear lower $(\mathrm{p}<0.05)$ than in the control group. Results from this study demonstrated that Bazhen supplement in chicken had several beneficial effects, including increased SRBC and ND titers, HDL and IgG, $\gamma$-globulin levels, PHA skin challenge result, decreased VLDL+LDL and GOT levels, and displayed antioxidation effects in serum and carcass meat parameters. (Key Words: Bazhen, Growth Performances, Serum Traits, Meat Quality, Antioxidant Activity, Chickens)
\end{abstract}

\section{INTRODUCTION}

To maintain animal health and promote growth performance, antibiotics can be added to animal rations. However, the overuse and misuse of antibiotics will lead to the development of drug-resistant bacteria, and the drug residues in the meat also threaten consumer health. Consequently, the drugs used become less effective, and some consumers have started to avoid certain meat products. In January 2006 the European Union (EU) approved a

\footnotetext{
* Corresponding Author: Tu-Fa Lien. Tel: +886-5-2717536, Fax: +886-5-2750134, E-mail: tflien@ mail.ncyu.edu.tw

${ }^{1}$ Graduate Institute of Clinical Medical Science, China Medical University, Taiwan.

${ }^{2}$ Department of Microbiology, Immunology, and Biopharmaceutics, National Chiayi University, Taiwan.

Submitted Feb. 15, 2012; Accepted Dec. 28, 2012; Revised Feb. 7, 2013
}

resolution to ban the use of antibiotics as growth promoter for animals. Many natural compounds used as alternatives to antibiotics in animal feed were shown to express positive effects on growth performance and body health parameters (Windisch et al., 2008).

Classical Chinese pharmacopoeia describes numerous herbal formulations that are used to treat a wide variety of diseases and conditions (Ergil, 1996). Many Chinese herbal medicines have been reported to boost immune system efficiency (Kong et al., 2004; Liao et al., 2010). Viscum album, Panax ginseng, Tinoapra coedifolia, and Asparagus racemosus, for instance, have all been shown to exert therapeutic properties (Davis and Kuttan, 2000), and Epimedium, Astragalosides, Ginsenoside and Glycyrrizae have displayed an immunological enhancement of chickens (Kong et al., 2004; Liu et al., 2010a). The components of polyphenol, flavonoids, polysaccharides, proteins and 
peptides (Kuttan and Kuttan, 1992) in herbal medicine reportedly stimulate the immune system and have antioxidant abilities. Thus, Chinese herbal medicine may be a potentially useful approach in the quest for a chemicalfree growth promoter.

The traditional Chinese prescription of Bazhen is composed of eight natural herbal medicines (Atractylodis Rhizoma, Codonopsitis Radix, Hoelen, Glycyrrhizae Radix, Angelicae Sinensis Radix, Ligustici Chuanxiong Rhizoma, Paeoniae Raix Rubra, and Rehmanniae Radix Rhizoma). Bazhen means eight kinds of precious herbal medicines and traditionally was used to remedy poor appetite, extreme tiredness, and dizziness. It is commonly used in China and Taiwan as a prescription for treating the diseases with deficiency of strength and blood, and is recognized as a safe natural herbal medicine. The phytochemical constituents of Bazhen include ferulic acid (a kind of polypenoid), atractylenolide, and flavonoids (include liquiritin, ginsenoside, and glycyrrhizic) (Chen et al., 2009; Li et al., 2012).

Generally, leftover chicken tastes inferior to freshly cooked chicken, which is a phenomenon caused by lipid peroxidation (Lin et al., 2003). They indicated that meat supplemented with antioxidant could maintain a fresh flavor for over a week.

We hypothesize that supplementing animal diets with phytochemicals exhibiting antioxidant property, may produce meat products that contain antioxidant substances and thus enhance meat quality.

Bazhen is rich of polyphenols and flavonoids. These characteristics encouraged us to test the hypothesis that Bazhen may benefit chicken health and production. This study, therefore, used Bazhen as an additive in chicken feed to investigate its influence on growth performances, serum traits, immunity, meat quality and antioxidant activity.

\section{MATERIAL AND METHODS}

\section{Animals and treatments}

One hundred and sixty d-old Taiwan country chicks (Taiwan native meat chickens) were used in this study. The chicks were assigned to four groups with four replicates and equal sex. The four groups of chicks were fed basal diets (Table 1) supplemented with $0,0.5,1$ and $2 \%$ of Bazhen. The chicks were allowed free access to feed and water. The study was conducted for a 14 wk period. Blood samples were taken (chickens were fasted overnight) from the wing vein at the end of the experiment, and centrifuged by $1,500 \times \mathrm{g}$ for $10 \mathrm{~min}$ to obtain serum. Also, at the end of the experiment, 16 chickens (eight males and eight females) of each group were sacrificed and liver and breast muscle were taken for analysis. Growth performances including feed intake, body weight gain and feed/gain ratio were
Table 1. Composition of the basal diets $(\mathrm{g} / \mathrm{kg})$

\begin{tabular}{|c|c|c|c|}
\hline & $0-4$ wks & $5-8$ wks & 9-14 wks \\
\hline \multicolumn{4}{|l|}{ Ingredients } \\
\hline Yellow corn meal & 639 & 584 & 653 \\
\hline Corn gluten meal & 85 & 50 & 47 \\
\hline Soybean meal, $44 \%$ & 77 & 153 & 98 \\
\hline Whole roasted soybean meal & 135 & 157 & 135 \\
\hline Fish meal, $60 \%$ & 30 & 30 & 3 \\
\hline Lard & 13 & 0 & 20 \\
\hline Dicalcium phosphate & 8 & 12 & 6 \\
\hline Limestone, pulverized & 5 & 6 & 4 \\
\hline Salt & 1 & 1 & 1 \\
\hline Vitamin premix $^{a}$ & 1 & 1 & 1 \\
\hline Mineral premix ${ }^{b}$ & 2 & 2 & 2 \\
\hline DL-methionine & 2 & 2 & 2 \\
\hline L-lysine & 2 & 2 & 1 \\
\hline Total & 1,000 & 1,000 & 1,000 \\
\hline \multicolumn{4}{|l|}{ Calculated value } \\
\hline Crude protein $(\mathrm{g} / \mathrm{kg})$ & 210.0 & 200.0 & 180.0 \\
\hline ME (kcal/kg) & 3,219 & 3,131 & 3,141 \\
\hline Calcium (g/kg) & 9.0 & 9.0 & 9.0 \\
\hline Total phosphorus (g/kg) & 7.0 & 7.0 & 7.0 \\
\hline Lysine (g/kg) & 12.6 & 11.0 & 10.4 \\
\hline Methionine+cystein (g/kg) & 9.2 & 8.2 & 7.8 \\
\hline \multicolumn{4}{|l|}{ Analyzed value } \\
\hline Crude protein $(\mathrm{g} / \mathrm{kg})$ & 212.0 & 205.0 & 178.0 \\
\hline
\end{tabular}

${ }^{a}$ Vitamin premix supplied the following per kilogram of diet: Vitamin A, 25,000 IU; Vitamin $\mathrm{D}_{3}$, 3,125 IU; Vitamin E, $37.5 \mathrm{IU}$; Vitamin $\mathrm{K}_{3}, 6.25$ $\mathrm{mg}$; Vitamin $\mathrm{B}_{1}, 3.75 \mathrm{mg}$; Vitamin $\mathrm{B}_{2}, 12.5 \mathrm{mg}$; Vitamin $\mathrm{B}_{6}, 10.0 \mathrm{mg}$; pantothenate, $18.8 \mathrm{mg}$; niacin, $50 \mathrm{mg}$; biotin, $0.06 \mathrm{mg}$; folic acid, $1.25 \mathrm{mg}$; Vitamin $\mathrm{B}_{12}, 0.05 \mathrm{mg}$.

${ }^{\mathrm{b}}$ Mineral premix supplied the following per kilogram of diet: $\mathrm{Cu}\left(\mathrm{CuSO}_{4}\right.$. $\left.5 \mathrm{H}_{2} \mathrm{O}, 25.45 \% \mathrm{Cu}\right) 6 \mathrm{mg}$; $\mathrm{Fe}\left(\mathrm{FeSO}_{4} .7 \mathrm{H}_{2} \mathrm{O}, 20.29 \% \mathrm{Fe}\right) 50 \mathrm{mg} ; \mathrm{Mn}$ $\left(\mathrm{MnSO}_{4} . \mathrm{H}_{2} \mathrm{O}, 32.49 \% \mathrm{Mn}\right) 40 \mathrm{mg} ; \mathrm{Zn}(\mathrm{ZnO}, 80.35 \% \mathrm{Zn}) 60 \mathrm{mg}$; Se $\left(\mathrm{NaSeO}_{3}, 45.56 \% \mathrm{Se}\right) 0.075 \mathrm{mg}$.

determined. Chickens used in this experiment were cared for under the guidelines stated in the Guide for the Care and Use of Agricultural Animals in Agricultural Research and Teaching, and this study was approved by the University's Animal Care and Use Committee.

Bazhen powder was purchased from a Chinese market, which contains eight kinds of commercial Chinese herbal medicines including Atractylodis Rhizoma (Atractylodes ovata A.P. De Candolle), Codonopsitis Radix (Codonopsis pilosula Nannfeldt), Hoelen (Poria cocos Wolf), Glycyrrhizae Radix (Glycyrrihiza uralensis Fischer et DC.), Angelicae Sinensis Radix (Angelica sinensis Diels), Ligustici Chuanxiong Rhizoma (Ligusticum chuanxiong Hortorum), Paeoniae Raix Rubra (Paeonia albiflora Pallas var. trichocarpa Bunge), and Rehmanniae Radix et Rhizoma (Rehmannia glutinosa Liboschitz).

\section{Liver sample preparation}

Approximately $5 \mathrm{~g}$ of fresh liver sample was 
homogenized under cold conditions $\left(4^{\circ} \mathrm{C}\right)$ with $10 \mathrm{ml}$ of $0.25 \mathrm{M}$ sucrose in $1 \mathrm{mM}$ EDTA-2Na buffer ( $\mathrm{pH} 7.4$ ). Next, the sample was centrifuged at $800 \times \mathrm{g}\left(4^{\circ} \mathrm{C}\right)$ for $10 \mathrm{~min}$ to remove debris and fat. The supernatant was further centrifuged at $10,300 \times \mathrm{g}\left(4^{\circ} \mathrm{C}\right)$ for $10 \mathrm{~min}$. Then, the supernatant was centrifuged by $105,000 \times \mathrm{g}\left(4^{\circ} \mathrm{C}\right)$ for $60 \mathrm{~min}$ (SW 41 rotor) with an ultracentrifuge (Beckman, model L-8, USA). Finally, the supernatant was stored at $-80^{\circ} \mathrm{C}$ for analysis of antioxidant activity.

\section{Serum traits measurement}

Total polyphenolics compounds in Bazhen were determined following the procedure described by Roura et al. (2006). Flavonoids content in Bazhen was measured based on the method reported by Zhishen et al. (1999). Serum lipoprotein profile was examined using electrophoresis, and the percentage of each band was determined by a densitometer (Helenna, Co., 8jf00105, USA), the value was express as percentage of total lipoprotein. Serum cholesterol, glutamic-oxaloacetic transaminase (GOT), and alanin-lactate transaminase (ALT) were measured using a serum autoanalyzer (Roche Co., Switzerland) with a commercial kit.

\section{Immunity traits measurement}

Immunoglobulin $\mathrm{G}$ ( $\mathrm{IgG}$ ) measurement was carried out using the methods of Leslie and Frank (1989) with an ELISA procedure. Each sample was tested in triplicate. First, the $50 \mu \mathrm{l}$ coating buffer (containing sodium carbonate $\left(\mathrm{Na}_{2} \mathrm{CO}_{3}\right)$ and sodium bicarbonate $\left(\mathrm{NaHCO}_{3}\right) 0.06 \mathrm{M}$ and capture antibody solution (rabbit anti-chicken IgG, with a ratio of 1:1,000) were put into a 96-well flat-bottom plate, cultured in an incubator at $37^{\circ} \mathrm{C}$ for $1 \mathrm{~h}$. and then washed 3 times with washing buffer (phosphate buffer solution and $0.05 \%$ Tween-20). Next, $50 \mu \mathrm{l} 1 \%$ BSA (bovine serum albumin) was added to each well, cultured for $1 \mathrm{~h}$, then washed 3 times and cultured again for $1 \mathrm{~h}$. After that, $100 \mu \mathrm{l}$ of sample was added with the detection of antibody solution (rabbit anti-chicken IgG conjugated with horseradish peroxidase, diluted 1:1,000 with PBS buffer) and incubated for $1 \mathrm{~h}$. After washing, $100 \mu \mathrm{l}$ 2,2'-azino-bis(3ethylbenzthiazoline-6-sulfonic acid (ABTS, as substrate, avoiding light) and $40 \mu \mathrm{H}_{2} \mathrm{O}_{2}$ were added to each well and allowed to stand for $15 \mathrm{~min}$. at room temperature. Finally, the values were measured by an ELASA reader (Multiskan Ascent, Finland) at $405 \mathrm{~nm}$ with Ascent software.

Sheep red blood cell (SRBC) antibody titer was examined in duplicate following the procedure described by Van Heugten et al. (1996). Black belly sheep blood was collected via the jugular vein into vials which contained $10 \%$ EDTA-2Na (disodium dihydrogen ethylenediamine tetraacetate dehydrate) (blood:EDTA, 10:1). An equal volume of sodium chloride solution was added and then mixed gently. This was followed by centrifugation at $670 \times \mathrm{g}$ for $10 \mathrm{~min}$, and then removed from the suspension. This process was repeated three times. Red blood cells were collected and diluted with isotonic sodium chloride solution to $0.25 \%$ SRBC. Each chicken was injected with $2 \mathrm{ml}$ SRBC intramuscularly in the 5th and 6th weeks of the experiment period. Blood samples were collected in the 7th week of the experiment, and then the SRBC antibody titer was measured by hemagglutination test. Fifty $\mu \mathrm{l}$ of serum sample was put into a U-type 96-well plate followed by dilution 2-fold afterwards with isotonic sodium chloride, then $50 \mu \mathrm{l}$ of $0.9 \%$ SRBC was added to each well. Hemagglutination was read after $1 \mathrm{~h}$.

Newcastle disease antibody titer was measured in duplicate by the hemagglutination inhibition test. Newcastle disease antigen was administered when the animals were 1 and 3 wks-old using active vaccine, and at 6 wks-old with inactive vaccine.

The phytohemagglutinin (PHA) (Sigma Chemicals Co.) challenged delayed type hypersensitivity (DTH) test was measured following the Kegley and Spear (1995) procedure. $150 \mu \mathrm{g} / \mathrm{ml}$ (in PBS) of PHA was injected intra-dermal into the wattles skin on the 14th week of experiment, then a micrometer was used to measure the degree of swelling from the injection area $24 \mathrm{~h}$ after the PHA injection.

To obtain the $\gamma$-globulin, the electrophoresis method was employed using a commercial kit (Helena Co. USA). The gel bands were scanned by a densitometer at $595 \mathrm{~nm}$ (Helena Co. 8JF00105, USA).

\section{Antioxidant traits measurement}

Glutathione peroxidase, superoxide dismutase (SOD) and catalase activities were assayed following the Ellerby and Bredesen (2000) procedure. Protein concentration was measured by the Lowry method (Lowry et al., 1951).

Thiobarbituric acid-reactive substances (TBARS) were examined following the procedure designed by Fraga et al. (1988). The ability of scavenging $\alpha$ - $\alpha$-diphenyl- $\beta$ picrylhydrazyl (DPPH) radical was examined according to the method of Hatano et al. (1989). Total glutathione (GSH) was assayed using the method of Bhat et al. (1992).

\section{Meat quality traits measurement}

The muscle $\mathrm{pH}$ was measured $24 \mathrm{~h}$ after post-mortem as described by Ockerman (1974). Muscle thiobarbituric acid (TBA) assay was modified from the methods of Tarlagis et al. (1960), Zipser and Watts (1962) and Ockerman (1974). Muscle metmyoglobin (met mb) was measured on postmortem as described by Kannan et al. (2001). Hunter "L", "a" and "b" values of muscles were recorded using a color and color difference meter (Model TC-1, Tokyo Denshoku Co., LTD, Japan), L, a and b mean light (brightness), 
Table 2. Effects of supplemented levels of Bazhen on the growth performance of Taiwan country chickens

\begin{tabular}{|c|c|c|c|c|c|c|c|}
\hline \multirow{2}{*}{ Variables } & \multicolumn{4}{|c|}{ Level of Bazhen (\%) } & \multirow{2}{*}{ SEM } & \multicolumn{2}{|c|}{$\mathrm{p}$ value } \\
\hline & 0 & 0.5 & 1 & 2 & & $\mathrm{~L}$ & $\mathrm{Q}$ \\
\hline Feed intake (kg) & 10.81 & 10.33 & 10.43 & 10.23 & 0.28 & 0.25 & 0.36 \\
\hline Body weight gain (kg) & 2.95 & 2.94 & 2.87 & 2.84 & 0.18 & 0.13 & 0.64 \\
\hline Feed/gain ratio & 3.66 & 3.54 & 3.21 & 3.60 & 0.25 & 0.31 & 0.38 \\
\hline
\end{tabular}

$\mathrm{n}=4$. $\mathrm{L}=$ Linear response. $\mathrm{Q}=$ Quadratic response.

Table 3. Effects of supplemented levels of Bazhen on serum traits of Taiwan country chickens

\begin{tabular}{|c|c|c|c|c|c|c|c|}
\hline \multirow{2}{*}{ Variables } & \multicolumn{4}{|c|}{ Level of Bazhen (\%) } & \multirow{2}{*}{ SEM } & \multicolumn{2}{|c|}{$\mathrm{p}$ value } \\
\hline & 0 & 0.5 & 1 & 2 & & $\mathrm{~L}$ & $\mathrm{Q}$ \\
\hline $\mathrm{HDL}^{1}(\%)$ & $36.73^{b}$ & $37.03^{\mathrm{b}}$ & $38.32^{\mathrm{b}}$ & $48.26^{\mathrm{a}}$ & 2.21 & 0.03 & 0.26 \\
\hline VLDL+LDL ${ }^{1}(\%)$ & $63.27^{\mathrm{a}}$ & $62.97^{\mathrm{a}}$ & $61.68^{a}$ & $51.94^{\mathrm{b}}$ & 2.21 & 0.03 & 0.26 \\
\hline $\mathrm{GOT}^{2}(\mathrm{U} / \mathrm{L})$ & $291.05^{\mathrm{a}}$ & $259.20^{\mathrm{ab}}$ & $303.20^{\mathrm{a}}$ & $224.10^{\mathrm{b}}$ & 14.31 & 0.35 & 0.04 \\
\hline $\mathrm{ALT}^{3}(\mathrm{U} / \mathrm{L})$ & 5.55 & 5.70 & 5.85 & 6.50 & 0.82 & 0.11 & 0.63 \\
\hline Cholesterol (mg/dl) & 145.20 & 154.20 & 153.40 & 161.20 & 6.73 & 0.32 & 0.58 \\
\hline
\end{tabular}

$\mathrm{n}=4 .{ }^{\mathrm{a}, \mathrm{b}}$ Means in the same row with different superscripts differ significantly $(\mathrm{p}<0.05)$.

${ }^{1} \mathrm{HDL}$ and VLDL+LDL values were express as $\%$ of total lipoprotein. ${ }^{2}$ GOT $=$ Glutamic-oxaloacetic transaminase. ${ }^{3}$ ALT $=$ Alanine aminotransferase.

$\mathrm{L}=$ Linear response; $\mathrm{Q}=$ Quadratic response.

amaranth (red indice), beige (yellow indice), respectively. Measurements were conducted in triplicate for each sample.

\section{Statistical analysis}

The proc mixed of SAS was used to analyze the multilevel model variance between groups, the significance difference between means was determined with the Tukey's test (SAS, 1998). According to the model,

$$
\mathrm{Y}=\mu+\mathrm{T}_{\mathrm{i}}+\mathrm{P}_{\mathrm{j}}+\mathrm{e}_{\mathrm{ijk}}
$$

$\mathrm{Y}$ is the dependent variable, $\mu$ represents the mean, $\mathrm{T}$ is the treatment effect $(I=4), P$ is the pen effect $(j=4)$ and $e$ is the random residual error term.

\section{RESULTS}

Bazhen contains flavonoids $183 \mu \mathrm{g} / \mathrm{kg}$ and polyphenols $850 \mu \mathrm{g} / \mathrm{kg}$. Thus, the diet contains $0,0.92,1.83$ and 3.66 $\mu \mathrm{g} / \mathrm{kg}$ of flavonoids, and $0,4.25,8.5$ and $17.0 \mu \mathrm{g} / \mathrm{kg}$ of polyphenols in $0,0.05,1$ and $2 \%$ Bazhen groups, respectively.

Table 2 lists the effects of supplemental levels of Bazhen on the growth performance of Taiwan country chickens. The feed intake, total body weight gain and feed/gain ratio did not differ significantly ( $p>0.05$ ) among groups.

Table 3 lists the effects of Bazhen supplementation on serum traits of Taiwan country chickens at the end of the experiment. HDL level linearly increased $(p<0.03)$ and VLDL+LDL level linearly decreased $(\mathrm{p}<0.03)$ in Bazhen supplemented groups, consequently the $2 \%$ group was different from the control group $(\mathrm{p}<0.05)$. The chickens fed with $2 \%$ Bazhen displayed reduced $(\mathrm{p}<0.05)$ GOT level. Bazhen supplementation had no effect $(p>0.05)$ on cholesterol concentration.

Table 4 represents the effects of Bazhen supplementation on the immune response of Taiwan country chickens. The IgG, $\gamma$-globulin levels and PHA skin challenge results displayed a quadratic response $(p<0.05)$ and in $1 \%$ Bazhan supplementation group was higher than in the control group $(\mathrm{p}<0.05)$. In addition, the SRBC and

Table 4. Effects of supplemented levels of Bazhen on immune response of Taiwan country chickens

\begin{tabular}{|c|c|c|c|c|c|c|c|}
\hline \multirow{2}{*}{ Variables } & \multicolumn{4}{|c|}{ Level of Bazhen (\%) } & \multirow{2}{*}{ SEM } & \multicolumn{2}{|c|}{$\mathrm{p}$ value } \\
\hline & 0 & 0.5 & 1 & 2 & & $\mathrm{~L}$ & $\mathrm{Q}$ \\
\hline Immunoglobulin G (mg/dl) & $22.4^{\mathrm{b}}$ & $25.2^{\mathrm{ab}}$ & $28.6^{\mathrm{a}}$ & $24.6^{\mathrm{ab}}$ & 1.6 & 0.15 & $<0.05$ \\
\hline SRBC titer ${ }^{1}\left(\log _{2}\right)$ & $3.73^{\mathrm{b}}$ & $4.77^{\mathrm{a}}$ & $4.81^{\mathrm{a}}$ & $4.94^{\mathrm{a}}$ & 0.12 & $<0.05$ & 0.17 \\
\hline ND $\operatorname{titer}^{2}\left(\log _{2}\right)$ & $10.42^{\mathrm{b}}$ & $12.42^{\mathrm{a}}$ & $13.58^{\mathrm{a}}$ & $13.32^{\mathrm{a}}$ & 0.16 & 0.04 & 0.11 \\
\hline PHA skin challenge ${ }^{3}(\mathrm{~mm})$ & $0.36^{\mathrm{b}}$ & $0.46^{\mathrm{ab}}$ & $0.55^{\mathrm{a}}$ & $0.48^{\mathrm{ab}}$ & 0.04 & 0.18 & $<0.05$ \\
\hline$\gamma$-globulin $(\mathrm{g} / \mathrm{dl})$ & $1.54^{\mathrm{b}}$ & $1.83^{\mathrm{ab}}$ & $1.94^{\mathrm{a}}$ & $1.71^{\mathrm{ab}}$ & 0.09 & 0.11 & 0.04 \\
\hline
\end{tabular}

$\mathrm{n}=4{ }^{\mathrm{a}}{ }^{\mathrm{a} b} \mathrm{M}$ Means in the same row with different superscript differ significantly $(\mathrm{p}<0.05)$.

${ }^{1} \mathrm{SRBC}=$ Sheep red blood cells. ${ }^{2} \mathrm{ND}=$ Newcastle disease. ${ }^{3} \mathrm{PHA}=$ Phytohemagglutinin.

$\mathrm{L}=$ linear response; $\mathrm{Q}=$ quadratic response. 
Table 5. Effects of supplemented levels of Bazhen on the antioxidative activity related traits of Taiwan country chicken livers

\begin{tabular}{|c|c|c|c|c|c|c|c|}
\hline \multirow{2}{*}{ Variables } & \multicolumn{4}{|c|}{ Level of Bazhen (\%) } & \multirow{2}{*}{ SEM } & \multicolumn{2}{|c|}{$\mathrm{p}$ value } \\
\hline & 0 & 0.5 & 1 & 2 & & $\mathrm{~L}$ & Q \\
\hline Total glutathione (nmole/mg protein) & $9.05^{\mathrm{a}}$ & $7.87^{\mathrm{a}}$ & $5.81^{\mathrm{ab}}$ & $2.70^{\mathrm{b}}$ & 1.25 & 0.01 & 0.28 \\
\hline Glutathione peroxidase (Unit/mg protein) & 297.86 & 294.31 & 285.99 & 287.80 & 8.37 & 0.23 & 0.37 \\
\hline Catalase (Unit/mg protein) & $5.51^{\mathrm{c}}$ & $26.65^{\mathrm{b}}$ & $55.14^{\mathrm{a}}$ & $56.10^{\mathrm{a}}$ & 9.34 & 0.03 & 0.21 \\
\hline Superoxide dismutase (Unit/mg protein) & 48.57 & 43.06 & 41.62 & 52.05 & 5.64 & 0.68 & 0.18 \\
\hline Scavenging DPPH $\operatorname{radical}^{1}(\%)$ & $78.49^{\mathrm{b}}$ & $81.81^{\mathrm{ab}}$ & $83.36^{\mathrm{a}}$ & $83.79^{\mathrm{a}}$ & 1.41 & 0.04 & 0.12 \\
\hline TBARS $^{2}$ (nM/mg protein) & $869.79^{\mathrm{a}}$ & $425.17^{\mathrm{b}}$ & $440.80^{b}$ & $322.99^{\mathrm{b}}$ & 19.92 & $<0.05$ & 0.04 \\
\hline
\end{tabular}

$\mathrm{n}=4{ }^{\mathrm{a}, \mathrm{b}, \mathrm{c}}$ Means in the same row with different superscripts differ significantly $(\mathrm{p}<0.05)$.

${ }^{1} \mathrm{DPPH}=\alpha$ - $\alpha$-diphenyl- $\beta$-picrylhydrazyl. ${ }^{2}$ TBARS $=$ Thiobarbituric acid-reactive substances.

$\mathrm{L}=$ Linear response; $\mathrm{Q}=$ Quadratic response.

ND titers in Bazhen supplemented groups were greater than in the control group $(\mathrm{p}<0.05)$ and showed a linear response $(\mathrm{p}<0.05)$.

Table 5 displays the effects of Bazhen supplementation on the antioxidative activity related traits of Taiwan country chickens liver. Catalase activity was linearly elevated $(\mathrm{p}<0.03)$ in the Bazhen supplemented groups and higher than the control group $(\mathrm{p}<0.05)$. The activities of glutathione peroxidase and superoxide dismutase were not significantly affected ( $p>0.05)$ by Bazhen supplementation. Compared to the control group, the level of scavenging DPPH radicals in 1 and 2\% Bazhen supplemented groups were linearly increased $(\mathrm{p}<0.05)$, and the TBARS levels in the Bazhen supplemented groups were linearly reduced $(p<0.05)$. Total glutathione was linearly reduced $(p<0.01)$ in Bazhen supplemented groups and in the $2 \%$ Bazhen supplemented group was different from the control group $(\mathrm{p}<0.05)$.

Table 6 presents the effects of Bazhen supplementation on the breast muscle quality traits of Taiwan country chickens. Breast muscle in Bazhen supplemented groups had linear lower $(\mathrm{p}<0.05) \mathrm{pH}$ than in the control. The breast muscle in the Bazhen supplemented groups displayed a linear lower $(\mathrm{p}<0.05)$ TBA value than the control. The breast muscle in the 0.5 and $2 \%$ Bazhen groups had higher $(\mathrm{p}<0.05)$ Hunter L values than the control. The Hunter $b$ value in the $0.5 \%$ Bazhen supplemented group was lower $(\mathrm{p}<0.05)$ than the control. Bazhen supplementation did not influent ( $p>0.05)$ the Met MB and Hunter a values of breast muscle.

\section{DISCUSSION}

Lipoprotein profile can affect coronary and heart health. The 2\% Bazhen group had a higher HDL and lower VLDL+LDL ratio than the control, indicating that Bazhen may be good for maintaining coronary and heart health. The serum GOT in the $2 \%$ Bazhen supplemented groups were lower than in the control. This finding indicates that Bazhen helps maintains animal health.

The $1 \%$ Bazhen supplemented groups had an elevated $\gamma$ globulin level. The level of $\gamma$-globulin is related to the antibody production capacity. The $\gamma$-globulins contain the immunoglobulins, including $\operatorname{IgA}, \operatorname{IgD}, \operatorname{IgE}$ and $\operatorname{IgG}$. IgG is the major immunoglobulin with the $1 \%$ Bazhen supplemented group also having elevated $\operatorname{IgG}$ levels. Therefore, Bazhen supplementation may protect animal health.

Free radical and lipid peroxidation have been implicated in the deterioration of many physiological functions including growth, reproduction and immunity (Gladine et al., 2007), and might also be involved in several pathological conditions, such as atherosclerosis, cancer and chronic inflammation (Halliwell, 1994; Hollman and Katan, 1997).

Epidemiological reports have indicated that

Table 6. Effects of supplemented levels of Bazhen on breast muscle quality of Taiwan country chicken

\begin{tabular}{|c|c|c|c|c|c|c|c|}
\hline \multirow{2}{*}{ Variables } & \multicolumn{4}{|c|}{ Level of Bazhen (\%) } & \multirow{2}{*}{ SEM } & \multicolumn{2}{|c|}{$\mathrm{p}$ value } \\
\hline & 0 & 0.5 & 1 & 2 & & $\mathrm{~L}$ & Q \\
\hline$\overline{\mathrm{pH}}$ & $5.98^{\mathrm{a}}$ & $5.78^{\mathrm{b}}$ & $5.73^{\mathrm{b}}$ & $5.71^{\mathrm{b}}$ & 0.03 & $<0.05$ & 0.08 \\
\hline $\mathrm{TBA}^{1}(\mathrm{meq} / \mathrm{kg})$ & $0.33^{\mathrm{a}}$ & $0.06^{\mathrm{b}}$ & $0.05^{\mathrm{b}}$ & $0.05^{\mathrm{b}}$ & 0.03 & $<0.05$ & 0.08 \\
\hline $\operatorname{MMB}^{2}(\%)$ & 47.55 & 48.27 & 51.56 & 50.56 & 2.14 & 0.63 & 0.71 \\
\hline L hunter $^{3}$ & $39.13^{b}$ & $41.90^{\mathrm{a}}$ & $41.07^{\mathrm{ab}}$ & $42.20^{\mathrm{a}}$ & 0.62 & 0.13 & 0.04 \\
\hline a hunter ${ }^{3}$ & 1.82 & 1.39 & 1.92 & 1.42 & 0.34 & 0.65 & 0.21 \\
\hline b hunter ${ }^{3}$ & $3.98^{\mathrm{a}}$ & $2.48^{\mathrm{b}}$ & $3.44^{\mathrm{ab}}$ & $4.17^{\mathrm{a}}$ & 0.28 & 0.23 & 0.06 \\
\hline
\end{tabular}

$\mathrm{n}=4$. $^{\mathrm{a}, \mathrm{b}}$ Means in the same row with different superscripts differ significantly $(\mathrm{p}<0.05)$.

${ }^{1} \mathrm{TBA}=$ Thiobarbituric acid. ${ }^{2} \mathrm{MMB}=$ Metmyoglobin. ${ }^{3} \mathrm{~L}=$ Light (brightness); $\mathrm{a}=$ Amaranth (red indice); $\mathrm{b}=\mathrm{beige}(\mathrm{yellow}$ indice)

$\mathrm{L}=$ Linear response; $\mathrm{Q}=$ Quadratic response. 
consumption of foods rich in flavonoids is associated with a lower incidence of degenerative diseases. Flavonoids or polyphenols compounds are natural phytochemical antioxidants that possess anti-inflammatory, antiviral, antiproliferative, and anticarcinogenic properties (Park et al., 2000). Flavonoids and polyphenols are rich in $\mathrm{OH}$ groups, and are recognized as excellent antioxidants (Deng et al., 1996; Jeon et al., 2001), and well known for keeping both humans and animals healthy. Damre et al. (2003) reported that using herbal medicines rich in flavonoids resulted in a significant dose response in sheep erythrocyte-specific haemagglutination antibody titer, and both the cell-mediated and the humoral components of the immune system were positively affected. This is in agreement with the current study where Bazhen supplementation groups had better SRBC and ND titers and the $1 \%$ group had higher IgG, $\gamma$-globulin levels and PHA skin challenge results than the control group (Table 4).

Reports in the literature have indicated that polyphenol is the active ingredient in some of the traditional herbal medicines used for treatment of disorders related to oxidative stress and inflammation (Joyenx et al., 1990; Dehmlow and Groot, 1996; Kobuchi et al., 1997; Wadsworth and Koop, 1999). Alvarez et al. (2006) indicated that prematurely aging mice, with lowered immune function that received polyphenols significantly increased in phagocytosis, microbicidal activity and natural killer activity in response to lipopolysaccharide and IL-2 release. Liu et al. (2010b) indicated that Bazhen could promote the proliferation and activation of $\mathrm{T}$ lymphocytes and significantly increase the secretion of IFN-gamma and IL-2. A culture media of spleen cells, macrophage, lung and skeletal muscle treated with Bazhen had a stimulating effect on mouse hematopoietic cells (Chun et al., 2004) indicating that Bazhen promoted the proliferation of bone marrow cells in anemic mice. Lien et al. (2007) also demonstrated that supplemental Bazhen enhanced the immune response of pigs and was a potential substitute for the antibiotics used in weaned piglets' feed.

DPPH radical scavenging ability was higher in the 1 and $2 \%$ Bazhen supplemented groups than in the control. The DPPH radical scavenging measured the hydrogen donor capacity of antioxidation systems. Meanwhile, total glutathione in the $2 \%$ Bazhen group was also lower than in the control group. Glutathione (GSH) is the most important molecule that animals require to keep healthy and prevent disease. In antioxidation systems GSH acts as a hydrogen donor, which neutralizes the free radicals. GSH is also critical in helping immune and detoxification systems (Brody, 1994). Since the GSH level decreased in dose a response manner to Bazhen supplementation it appears that Bazhen was stimulating the action of glutathione in antioxidation systems as a hydrogen donor to scavenge radicals.

Catalase can remove the hydrogen peroxide radical $(\mathrm{HOOH})$ by catalyzing two $\mathrm{HOOH}$ molecules to form two molecules of water and one molecule of $\mathrm{O}_{2}$. Experimental results showed that supplemental 1 and $2 \%$ Bazhen raised the catalase activity compared to the control. This means that Bazhen can increase scavenging of $\mathrm{HOOH}$ radicals. Superoxide dismutase (SOD) catalyzes the dismutation of superoxide into oxygen and hydrogen peroxide. Supplementation with Bazhen did not affect SOD activity in this study.

TBARS concentration was lower in the Bazhen supplemented groups than in the control. TBARS measures the products of lipid oxidation such as malondialdehyde (MDA). Bazhen appears to be able to prevent lipid oxidation of chicken liver, and thus Bazhen supplementation may benefit animal health.

Bazhen is abundant in flavonoids and polyphenols. Flavonoids contain $3 \mathrm{OH}$-groups which can supply $\mathrm{H}$ atoms to quench free radicals, thus making them strong antioxidant (Deng et al., 1996; Jeon et al., 2001). Therefore, Bazhen has antioxidant activity theoretically.

Tang et al. (2000; 2001) indicated that dietary supplementation of tea catechins which contains polyphenol compounds could effectively reduce the TBA value of chicken breast muscle. The present study also showed that breast muscle in the Bazhen supplemented groups had lower TBA value than the control.

Meat color and lipid stability are major factors limiting the quality and acceptability of meat products by consumers (Yang et al., 2002). Lipid oxidation results in free radical production, leading to the oxidation of meat pigments and generation of rancid odors and flavors. The breast muscle in the 0.5 and $2 \%$ Bazhen groups displayed higher Hunter L values than the control, which may also pertain to the antioxidant ability of Bazhen supplementation.

\section{CONCLUSIONS}

The results of this study demonstrated that supplementing chicken diets with Bazhen has beneficial effects, including increased HDL, SRBC and ND titers, IgG, $\gamma$-globulin levels, PHA skin challenge result and decreased VLDL+LDL and GOT levels. Furthermore, it produced antioxidative effects in serum and carcass meat parameters, even though there were no effects on growth performances. From the results of this study, we suggest supplementing at a level of about 0.5 to $1 \%$ as being appropriate for broiler chickens.

\section{REFERENCES}

Álvarez, P., C. Alcvarado, M. Puerto, A. Schlumberger, L. Jiménez 
and M. D. I. Fuente. 2006. Improvement of leukocyte functions in prematurely aging mice after five weeks of diet supplementation with polyphenol-rich cereals. Nutrition 22:913-921.

Bhat, G. B., S. B. Tinsley, J. K. Tolson, J. M. Patel and E. R. Block. 1992. Hypoxia increases the susceptibility of pulmonary artery endothelial cells to hydrogen peroxide injury. J. Cell Physiol. 151:228-238

Brody, T. 1994. Nutritional Biochemistry. Academic Press, Inc. London. p. 597-608.

Chen, D., S. S. Zhao and K. S. Leung. 2009. Improved quality assessment of proprietary Chinese medicines based on multichemical class fingerprinting. J. Sep. Sci. 32:2892-2902.

Chun, Z., X. Luo, D. Chen, M. Yu, Y. Cheng and Z. Yang. 2004. The influence of Bazhen decoction on hematopoietic modulator in anaemic mice. Sheng Wu Yi Xue Gong Cheng Xue Za Zhi. 21:727-731

Damre, A. S., A. B. Gokhale, A. S. Phadke, K. R. Kulkarni and M. N. Saraf. 2003. Studies on the immunomodulatory activity of flavonoidal fraction of Tephrosia purpurea. Fitoterapia. 74:257-261.

Davis, L. and G. Kuttan. 2000. Immunomodulatory activity of Withania somnifera. J. Ethnopharmacol. 71:193-200.

Dehmlow, C., J. Erhard and H. de Groot. 1996. Inhibition of Kupffer cell functions as an explanation for the hepatoprotective properties of silibinin. Hepatology 23:749754.

Deng, W., X. Fang and J. Wu. 1996. Flavonoids function as antioxidants: by scavenging reactive oxygen species or by chelating iron. Radiat. Phys. Chem. 50:271-276.

Ellerby, L. M. and D. E. Bredesen. 2000. Measurement of cellular oxidation, reactive oxygen species, and antioxidant enzymes during apotosis. Methods Enzymol. 322:413-421.

Ergil, K. V. 1996. China's traditional medicine. In: Fundamentals of complementary and Alternative Medicine (Ed. M. S. Micozzi). Liveingstone, New York. USA. p. 185-223.

Fraga, C. G., B. E. Leibovitz and A. L. Tappel. 1988. Lipid peroxidation measured as thiobarbituric acid-reactive substance in tissue slices: Characterization and comparison between homogenates and microsome. Free Radic. Biol. Med. 4:155-161.

Gladine, C., C. Morand, E. Rock, D. Gruffat, D. Bauchart and D. Durand. 2007. The antioxidative effect of plant extracts rich in polyphenols differs between liver and muscle tissues in rats fed n-3 PUFA rich diet. Anim. Feed Sci. Technol. 139:257-272.

Halliwell, B. 1994. Free radicals, antioxidants, and human disease: curiosity, cause, or consequence? Lancet 344:721-724.

Hatano, T., R. Edamatsu, A. Mori, Y. Fujita, T. Yasuhara, T. Yoshida and T. Okuda. 1989. Effects of the interaction of tannins with co-existing substances. VI. Effects of tannins and related polyphenols on superoxide aniom radical, and on 1,1diphenyl-pierylhydrazyl radical. Chem. Pharm. Bull. 37:20162021.

Hollman, P. C. and M. B. Katan. 1997. Absorption, metabolism and health effects of dietary flavonoids in man. Biomed. Pharmacother. 51:305-310.

Jeon, S. M., S. H. Bok, M. K. Jang, M. K. Lee, K. T. Nam, Y. B. Park, S. J. Rhee and M. S. Choi. 2001. Antioxidative activity of naringin and lovastatin in high cholesterol-fed rabbits. Life Sci. 69:2855-2866.

Joyenx, M., A. Rolland, J. Fleurentin, F. Mortier and P. Dorfman. 1990. Tert-butyl hydroperoxide-induced injury in isolated rat hepatocytes: A model for studying anti-hepatotoxic crude drugs. Planta. Med. 56:171-174.

Kannan, G., B. Kouakou and S. Gelaye. 2001. Color changes reflecting myoglobin and lipid oxidation in chevon cuts during refrigerated display. Small Rumin. Res. 42:67-74.

Kegley, E. B. and J. W. Spears. 1995. Immune response, glucose metabolism, and performance of stressed feeder calves fed inorganic or organic chromium. J. Anim. Sci.73:2721-2726.

Kobuchi, H. M., T. Droy-Lefaix, Y. Christen and L. Packer. 1997. Ginkgo biloba extract (EGb 761): Inhibitory effect on nitric oxide production in the macrophage cell line RAW264. 7. Biochem. Pharmacol. 53:897-903.

Kong, X., Y. Hu, R. Rui, D. Wang and X. Li. 2004. Effects of Chinese herbal medicinal ingredients on peripheral lymphocyte proliferation and serum antibody titer after vaccination in chicken. Int. Immunopharmcol. 4:975-982.

Kuttan, G. and R. Kuttan. 1992. Immunomodulatiry activity of a peptide isolated from Viscum album extract. Immunol. Invest. 21:285-296.

Leslie, H. and C. H. Frank. 1989. Practical Immunology. 3rd Ed. Blackwell Scientific, London. p. 23.

Li, W., J. Bai, M. Wang and Y. Ji. 2012. Identification of the chemical constituents of bazhen decoction in rat feces by high performance liquid chromatography electro spray ionization mass spectrometry (HPLC/ESI/MS). J. Med. Plant Res. 6:2601-2605

Liao, H. F., M. C. Lu, H. C. Chang, C. C. Wei, C. H. Kao, Z. H., Chen, C. C. Huang and C. Li. 2010. Effects of herbal medicinal formulas on suppressing viral replication and modulating immune responses. Am. J. Clin. Med. 38:173-190.

Lien, T. F., Y. M. Horng and C. P. Wu. 2007. Feasibility of replacing antibiotics feed promoters with the Chinese traditional herbal medicine Bazhen in weaned pigs. Livest. Sci. 107:97-102.

Lin, K. J., T. F. Tseng, C. K. Chou and S. L. Huang. 2003. Antioxidant effect of Chinese herbal medicines (Bazhen powder) used in the formulation on Chinese-style semi-dry sausage. J. Biomass Energy Soc. China 21:47-56.

Liu, F. X., S. Sun and Z. Z. Cui. 2010a. Analysis of immunogical enhancement of immunosuppression chickens by Chinese herbal extracts. J. Ethnopharmacol. 127:251-256.

Liu, X., X. Wang, Z. Li, Y. Chen and J. Chen. 2010b. In vitro study for detecting the effects of Bazhen decoction on proliferation and activation of T lymphocytes. Sheng Wu Yi Xue Gong Cheng Xue Za Zhi. 27:855-858.

Lowry, O. H., N. J. Rosebrough, A. L. Farr and R. J. Randall. 1951. Protein measurement with Folin-phenol reagent. J. Biolog. Chem. 193:265-275.

Ockerman, H. W. 1974. Quality control of post-mortem muscle tissue. 9th ed., Animal Science Dept. The Ohio State University. Columbus, OH. USA. p. 91.

Park, Y. C., G. Rimbach, C. Saliou, G. Valacchi and I. Packer. 2000. Activity of monomeric, dimeric, and trimeric flavonoids on NO production, TNF- $\alpha$ secretion, and NF- $\kappa \mathrm{B}$-dependent gene 
expression in RAW 264.7 macrophaages. FEBS Lett. 465:9397.

Roura, E., C. Andrés-Lacueva, R. Estruch and R. M. LamuelaRaventós. 2006. Total polyphenol intake estimated by a modified Folin-Ciocalteu assay of urine. Clin. Chem. 52:749752.

Statistical Analysis System Institute. 1998. SAS/STAT User's guide, Version 6.06, 4th ed. Cary, NC.

Tang, S. Z., J. P. Kerry, D. Sheehan, D. J. Buckley and P. A. Morrissey. 2000. Dietary tea catechins and iron-induced lipid oxidation in chicken meat, liver and heart. Meat Sci. 56:285290.

Tang, S. Z., J. P. Kerry, D. Sheehan, D. J. Buckley and P. A. Morrissey. 2001. Antioxidative effect of dietary tea catechins on lipid oxidation of long-term frozen stored chicken meat. Meat Sci. 57:331-336.

Tarlagis, B. G., B. M. Watts, M. T. Younathan and L. Dugan. 1960. A distillation method for the quantitative determination of malonaldehyde in rancid foods. J. Am. Oil Chem. Soc. 37:4448.
Van Heugten, E., M. T. Coffey and J. W. Spears. 1996. Effects of immune challenge, dietary energy density and source of energy on performance and immunity in weanling pigs. J. Anim. Sci. 74:2431-2440.

Wadsworth, T. L. and D. R. Koop. 1999. Effects of the wine polyphenolics quercetin and resveratrol on pro-inflammatory cytokine expression in RAW 264.7 macrophages. Biochem. Pharmacol. 57:941-949.

Windisch, W., K. Schedle, C. Plitzner and A. Kroismayr. 2008. Use of phytogenic products as feed additives for swine and poultry. J. Anim. Sci. 86:E140-E148.

Yang, A., M. J. Brewster, M. C. Lanari and R. K. Tume. 2002. Effect of vitamin $\mathrm{E}$ supplementation on $\alpha$-tocopherol and $\beta$ carotene concentrations in tissues from pasture and grain-fed cattle. Meat Sci. 60:35-40.

Zhishen, J., T. Mengcheng and W. Jianming. 1999. The determination of flavonoid content in mulberry and their scavenging effects on superoxide radicals. Food Chem. 64:555-559.

Zipser, M. W. and B. M. Watts. 1962. A modified 2-thiobarbituric acid method for the determination of malonaldehyde in cured meats. Food Technol. 16:102-104. 